Louisiana State University

LSU Digital Commons

Faculty Publications

Department of Biological Sciences

$1-1-2001$

\title{
Sexual selection on plumage and behavior in an avian hybrid zone: Experimental tests of male-male interactions
}

\author{
David B. McDonald \\ University of Wyoming \\ Robert P. Clay \\ University of Cambridge \\ Robb T. Brumfield \\ University of Washington, Seattle \\ Michael J. Braun \\ Smithsonian Institution
}

Follow this and additional works at: https://digitalcommons.Isu.edu/biosci_pubs

\section{Recommended Citation}

McDonald, D., Clay, R., Brumfield, R., \& Braun, M. (2001). Sexual selection on plumage and behavior in an avian hybrid zone: Experimental tests of male-male interactions. Evolution, 55 (7), 1443-1451.

https://doi.org/10.1111/j.0014-3820.2001.tb00664.x

This Article is brought to you for free and open access by the Department of Biological Sciences at LSU Digital Commons. It has been accepted for inclusion in Faculty Publications by an authorized administrator of LSU Digital Commons. For more information, please contact ir@lsu.edu. 


\title{
SEXUAL SELECTION ON PLUMAGE AND BEHAVIOR IN AN AVIAN HYBRID ZONE: EXPERIMENTAL TESTS OF MALE-MALE INTERACTIONS
}

\author{
David B. McDonald, ${ }^{1,2}$ Robert P. Clay, ${ }^{3}$ Robb T. Brumfield, ${ }^{4,5}$ and Michael J. Braun 6,7 \\ ${ }^{1}$ Department of Zoology and Physiology, University of Wyoming, Laramie, Wyoming 82071-3166 \\ ${ }^{2}$ E-mail: dbmcd@uwyo.edu \\ ${ }^{3}$ Large Animal Research Group, Department of Zoology, University of Cambridge, Downing Street, \\ Cambridge CB2 3EJ, United Kingdom \\ ${ }^{4}$ Department of Zoology, Box 351800, University of Washington, Seattle, Washington 98112 \\ ${ }^{5}$ E-mail: brumfld@u.washington.edu \\ ${ }^{6}$ Laboratory of Molecular Systematics, Smithsonian Institution, Washington, D.C. 20560 \\ ${ }^{7}$ E-mail: braun@onyx.si.edu
}

\begin{abstract}
In western Panama, an unusual hybrid zone exists between white-collared manakins, Manacus candei, and golden-collared manakins, M. vitellinus. Unidirectional introgression of plumage traits from vitellinus into candei has created a region in which all definitively plumaged males have a collar that is lemon-colored. These males are nearly indistinguishable from white-collared candei genetically and morphometrically, but strongly resemble golden-collared vitellinus due to the introgression of secondary sexual plumage traits, particularly the lemon-colored collar. The introgression could be explained by sexual selection for golden-collared traits or by a series of mechanisms that do not invoke sexual selection (e.g., neutral diffusion, dominant allele). Sexual selection on male-male interactions implies behavioral differences among the plumage forms - specifically that golden- and lemon-collared males should be more aggressive than white-collared males. In contrast, the nonsexual hypotheses predict behavioral similarity between lemon- and white-collared males, based on their nearly identical genetics. We tested the sexual selection hypothesis experimentally, by presenting males with taxidermic mounts of the three forms. As response variables, we monitored vocalizations and attacks on the mounts by replicate subject males. Both golden-collared and lemon-collared males were more likely to attack than were white-collared males, as predicted under sexual selection but not by the nonsexual hypotheses. Lemon-collared males were more vocally reactive than either parental form, contrary to the prediction of the nonsexual hypotheses. Our study demonstrates that sexual selection on male-male interactions may play an important role in the dynamics of character evolution and hybrid zones.
\end{abstract}

Key words.-Aggression, asymmetric introgression, character evolution, lek, manakin, shifted clines, speciation.

Received October 20, 2000. Accepted March 19, 2001.

Hybrid zones provide unusual opportunities to examine a variety of evolutionary processes that relate to geographic variation and character evolution (Hewitt 1988; Barton and Hewitt 1989; Barton 1993; Harrison 1993). Especially intriguing are cases of differential introgression, in which traits from one population or species spread into another (Avise 1994; Shoemaker et al. 1996; Grant and Grant 1997). To some degree, such differential movements are expected for neutral or advantageous traits, even in cases where there is selection against hybrids (Barton 1979; Barton and Bengtsson 1986). It may be difficult to detect such movements of traits, however, because advantageous traits will sweep to fixation in all populations, leaving no differences between parental forms (Hewitt 1988). By providing a conduit for the passage of traits between differentiated populations, hybrid zones may therefore play an important but underappreciated role in evolution.

In western Panama, a hybrid zone exists between the white-collared manakin, Manacus candei, and the goldencollared manakin, M. vitellinus, two closely related, sexually dichromatic, lek-mating birds (Fig. 1). The hybrid zone is unusual in that some secondary sexual plumage traits of vitellinus appear to have introgressed unidirectionally into candei populations (Parsons et al. 1993). Like most hybrid zones (Moore 1977), the manakin zone is characterized by numerous steep and coincident clines in morphometric and genetic characters (Parsons et al. 1994; Brumfield 1999). However, clines for male collar color and belly color, the two characters responsible for the visually striking differences between the two species, are displaced $50 \mathrm{~km}$ to the west, where they undergo a similarly steep transition across the Río Changuinola (Brumfield 1999). Birds in the region between the two sets of clines are nearly indistinguishable, morphometrically and genetically, from white-collared males, yet look like golden-collared males because of the introgression of vitellinus plumage traits. The most obvious of these introgressing traits is the lemoncolored collar.

In this paper we present experimental tests of mutually exclusive hypotheses for the introgression: positive sexual selection on the plumage traits (Parsons et al. 1993) versus a suite of mechanisms that do not invoke sexual selection. To test these hypotheses, we presented taxidermic mounts of the three plumage forms (and various controls) to white-, golden-, and lemon-collared males and recorded their responses. Responses to mounts could occur in several ways (Rohwer 1982). Males might perceive a threat and vocalize, without a connotation of aggression (as when reacting to a predator). Alternatively, vocalizations might be part of an aggressive continuum extending to physical attacks, with risk of injury to both attacker and attacked. Clearly, though, vocalizations are less aggressive than are physical attacks. In studies of blackbirds, relative aggression toward mounts accurately predicted the winners of staged contests between mount-treated subject males (Rohwer 1982). 


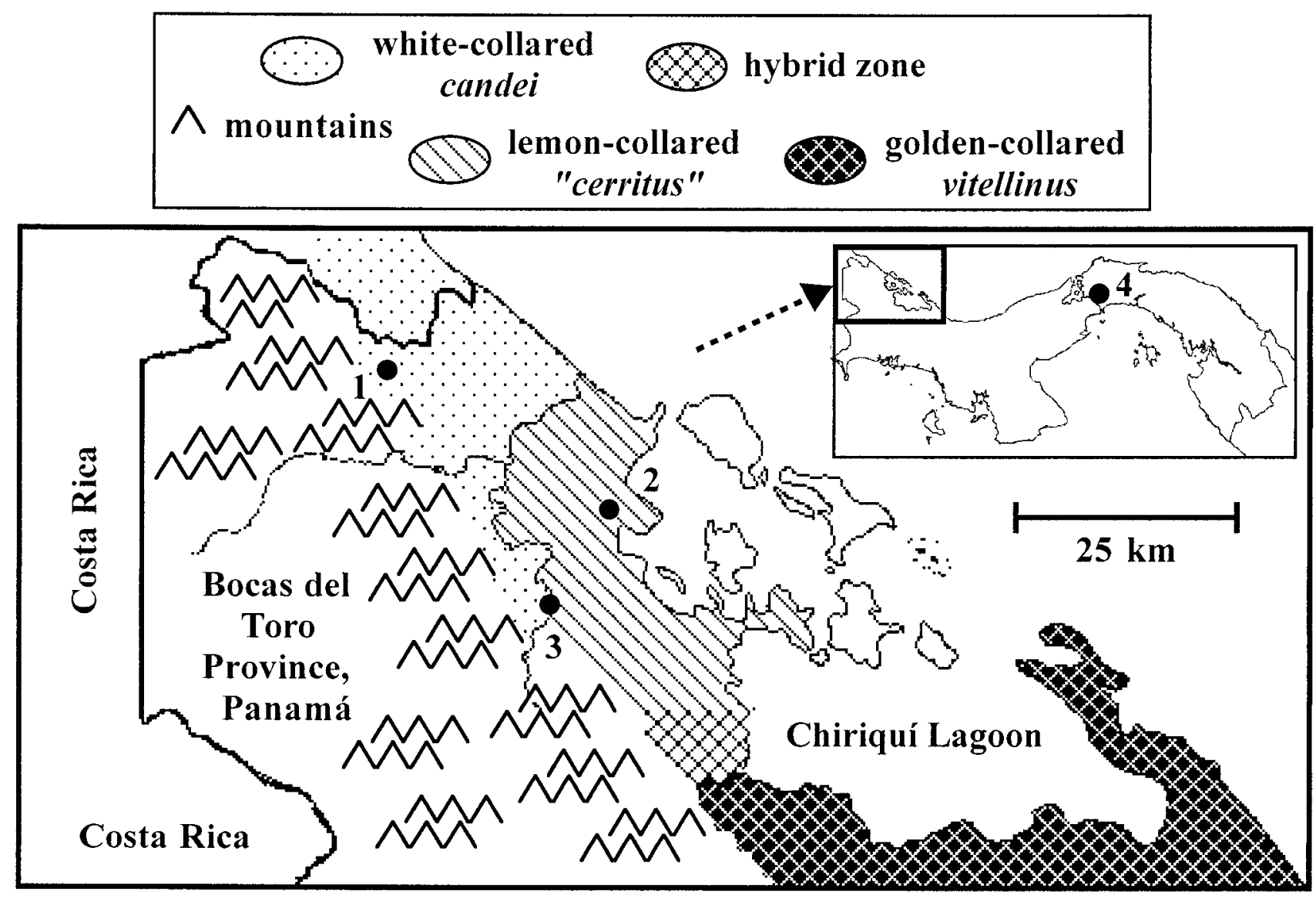

FIG. 1. Manacus hybrid zone and study sites along the Chiriquí Lagoon, Bocas del Toro province, Panama, near the Costa Rican border. The coarse-grained subdivision into four geographic areas ignores some subtleties of cline structure. For more details, see Brumfield (1999). Filled circles represent experimental sites: (1) two Río SanSan lek arenas containing only white-collared males; (2) two Almirante lek arenas containing only introgressed lemon-collared males; (3) two leks along each bank of the upper Río Changuinola, containing mixtures of white- and lemon-collared males; and (4) leks near the Panama canal, containing only golden-collared males (inset). Site 4 is approximately $250 \mathrm{~km}$ to the east of sites 1,2, and 3. North and west of the lemon-collared zone, beyond the Río Changuinola and into Costa Rica, all males were white-collared (pure M. candei). South and east of the hybrid zone all males were golden-collared (pure M. vitellinus). Mountains to the west are unsuitable habitat for Manacus. Sites 1, 2, and 4 correspond most closely to populations 2, 5, and 10, respectively, of Parsons et al. (1993).

\section{Sexual Selection Hypothesis}

Parsons et al. (1993) proposed that sexual selection on these lek-mating birds might be driving the differential introgression of golden-collared plumage traits across the hybrid zone, producing the displaced clines for secondary sexual traits. Sexual selection can operate through female choice or male-male interactions. Females might mate preferentially with golden-collared males, or golden-collared males might outcompete white-collared males for preferred courts on lek arenas (Beehler and Foster 1988). The present experiments focus on male-male interactions. If sexual selection acts largely through male-male interactions, the plumage variation should correspond to variation in male behavior. When different plumage forms meet, for example, males that respond most aggressively to any Manacus-like plumage might be favored competitively in securing courts. Implicit in the sexual selection hypothesis, therefore, is an inherent parental difference in behaviors related to reproduction. Because of the unidirectional introgression of golden-collared traits into white- collared populations, we predicted that parental goldencollared (vitellinus) males should be inherently more aggressive than parental white-collared (candei) males.

The sexual selection hypothesis also has implications for the behavior of lemon-collared males. The introgressed lemon-collared males should resemble golden-collared males not just in plumage but also in behavior-most specifically in their aggression toward Manacus males. Finally, because introgressed lemon-collared males are necessarily descendants of males that competed with two visually distinct forms (the white- and golden-collared interactors in the original contact zone), sexual selection should have favored males that reacted to all Manacus males, regardless of variation in plumage color or pattern. Vocalizations directed toward aggressive golden-collared males might reduce risk of attack, whereas those toward white-collared males might simply represent recognition of a potential sexual rival, despite the difference in plumage coloration. Lemon-collared males might therefore be more reactive vocally than either parental form to intrusions by any Manacus-like male. 


\section{Nonsexual Hypotheses}

A series of genetic, demographic, and historic mechanisms might explain the shifted plumage clines without invoking sexual selection. We term these collectively the nonsexual hypotheses. They include several mechanisms specifically suggested by Butlin and Neems (1994) for this hybrid zone: neutral diffusion, dominant alleles, or an artifact of nonlinear color scales for the introgressing plumage traits. Other mechanisms for asymmetric hybrid zones suggested by Jaarola et al. (1997) include discrete incompatibility of the parental genomes, founder effects, and historical movement. Regardless of the particular hypothesis invoked, all the nonsexual alternatives have in common several contrasts to the predictions of the sexual selection hypothesis. First, they require no special link between plumage and behavior. They do not, therefore, predict behavioral differences between the parental forms. Second, because of the nearly identical genetic and morphometric traits between lemon-collared and white-collared males, these hypotheses do predict that those two forms should behave similarly.

In the present paper, we ask first whether the parental forms (golden- and white-collared) differ in their aggression toward Manacus mounts, as predicted by the sexual selection hypothesis. Second, we ask whether the aggressive responses of lemon-collared males resemble those of white-collared males (as predicted by the nonsexual hypotheses) or those of golden-collared males (as predicted under sexual selection). Third, we ask whether the vocal reactivity of introgressed lemon-collared males in the presence of Manacus taxidermic mounts exceeds the reactivity of the two parental forms.

\section{Materials ANd Methods}

\section{Terminology, Natural History, and Study Sites}

The most visually striking plumage differences between males of white-collared $M$. candei and golden-collared $M$. vitellinus are in the color of the collar and throat (candei white, vitellinus golden) and the color of the belly (candei lemon, vitellinus green). The coloration of introgressed males differs subtly from that of golden-collared males in the shade of the throat/collar (lemon vs. golden) and belly (greenish lemon vs. green). There is also more variability in the color of introgressed males, as might be expected from their hybrid origin. Brumfield (1999) provided a detailed, spectrophotometric analysis of color variation across the hybrid zone. Lemon-collared birds were originally named as a separate species, M. cerritus (Peters 1927), and more recently have been treated as a subspecies of $M$. vitellinus (American Ornithologists' Union 1983).

We refer to the three forms by the collar color of males: white-collared for $M$. candei, lemon-collared for introgressed M. "cerritus,', and golden-collared for $M$. vitellinus. We refer to the three forms of taxidermic mounts as white, lemon, and golden, respectively. Males of all four Manacus species perform very similar courtship displays at traditional lek arenas. Individuals clear the leaf litter from small, well-defined courts ( $\sim 1$-m diameter) containing one or more vertical saplings used as the focus for saltatory displays, which are accom- panied by loud snaps (Snow 1962; Lill 1974). As many as 50 males may occupy an area $\leq 2$ ha. Intercourt spacing in our study ranged from $<5 \mathrm{~m}$ to $\sim 25 \mathrm{~m}$. The display season is long (more than six months). All treatments were performed between mid-March and mid-June (straddling the height of display in May) between March 1995 and June 1996. We individually color-banded most of the court-holding males in 1994, the year prior to the first experiments, and used only color-banded males as experimental subjects.

We presented mounts to males at six pure lek arenas (lek members all of the same form), equally divided among the three plumage forms, with a few supplementary treatments at mixed leks. Our study sites, as numbered in Figure 1, were (1) two pure white-collared leks, near the Río SanSan in Bocas del Toro Province, western Panama $\left(9^{\circ} 27.1^{\prime} \mathrm{N}\right.$, $\left.82^{\circ} 40.3^{\prime} \mathrm{W}\right)$; (2) two pure lemon-collared leks, along the railroad between Almirante and Changuinola, Bocas del Toro, Panama $\left(9^{\circ} 18.3^{\prime} \mathrm{N}, 82^{\circ} 24.9^{\prime} \mathrm{W}\right)$; (3) a few supplementary treatments along the banks of the upper Río Changuinola $\left(9^{\circ} 12.5^{\prime} \mathrm{N}, 82^{\circ} 28.5^{\prime} \mathrm{W}\right)$, the only location where different forms (white- and lemon-collared) currently coexist; and (4) two pure golden-collared leks, along Pipeline Road in Soberanía National Park near Gamboa, Panama $\left(09^{\circ} 8.0^{\prime} \mathrm{N}, 79^{\circ} 43.3^{\prime} \mathrm{W}\right)$, and along ChivaChiva Road $\left(09^{\circ} 2.2^{\prime} \mathrm{N}, 79^{\circ} 34.7^{\prime} \mathrm{W}\right)$. Sites 1,2 , and 4 correspond most closely to populations 2 (pure white-collared), 5 (pure lemon-collared), and 10 (pure golden-collared), respectively, of Parsons et al. (1993). Lek sizes ranged from approximately 15 to approximately 30 court-owning males.

\section{Experimental Design and Protocols}

The experimental design resembled that of McDonald's (1993) intraspecific experiments with long-tailed manakins, Chiroxiphia linearis. Five observers presented subject males with six types of treatment: (1) wooden stands, like those used for attaching the taxidermic mounts, as a treatment control; (2) taxidermically mounted Swainson's thrushes, Catharus ustulatus, to assess reaction to a neutral (nonmanakin) avian intruder; the thrushes had none of the secondary sexual colors or pattern (black, yellow, white, or green patches) of male Manacus; $(3,4,5)$ taxidermic mounts of males of the three forms: parental white- and golden-collared and introgressed lemon-collared; and (6) rubber snakes, as examples of a potential predator and known threat. The model snakes resembled eyelash vipers, Bothrops schlegelli, which we saw on at least 10 occasions at Río SanSan. We also presented a green-plumaged female candei mount (females of all Manacus species are very similar) to six lemon-collared males. The purpose of the female mount presentations was to assess the reaction to conspecifics that did not bear the secondary sexual plumage colors. If the secondary sexual trait of plumage color is functionally important in the context of malemale interactions, we would expect the response toward green female mounts to differ from that toward male Manacus mounts. All mounts were prepared in a neutral pose. To reduce effects of responses induced by a particular mount posture or plumage condition, we used two to four different mounts of each Manacus form, and randomized their assignment to treatments. 
At each lek arena, we randomly selected approximately eight color-banded male subjects, avoiding immediate neighbors once we chose a particular subject. A 30-min observation period (temporal control) preceded each treatment, to assess the impact of variation in background level of activity due to time of day, weather, or other factors. We presented the six treatment types to each subject male in random order, with intertreatment intervals of at least one day (range $=1.0$ 8.0 days, mean $=2.4$ ). We placed the treatment $25-50 \mathrm{~cm}$ from the edge of the well-defined courts. Data collection began when the court-owner approached within approximately $5 \mathrm{~m}$ of the court, and continued for $30 \mathrm{~min}$. The intent was to initiate monitoring when the court owner was close enough to have seen the treatment if one were present. For example, no treatment was present during the temporal control but data collection nevertheless began only upon close approach of the court owner. Presentations began between 07:30 $\mathrm{h}$ and 16:30 $\mathrm{h}$, and start time was randomized within the constraints of bouts of fieldwork at different study sites. The observer sat in a temporary blind 8-12 $\mathrm{m}$ from the edge of the court.

\section{Treatment Design and Variables Monitored}

The nature of plumage variation affected our comparisons of treatment responses. The lemon plumage resembles the golden much more closely than it does the white. Across the hybrid zone the change in throat/collar color between lemon and golden is subtle and graded both to the eye (Parsons et al. 1994) and when quantified by reflectance spectrophotometry (Brumfield 1999), whereas that between white and either lemon or gold is large and steplike. If presented with all three mount forms, white-collared males would face two mount forms very dissimilar to themselves, and potentially unfamiliar enough not to be recognized as sexual rivals. In contrast, golden- and lemon-collared males would face only one dissimilar mount. We therefore restricted analyses to two of the three mount forms to avoid a potential source of bias that would tend to favor the sexual selection hypothesis. That is, we based comparisons on the mean of a male's responses to his own mount form (similar) and a dissimilar mount form (white for lemon- and golden-collared males, golden for white-collared males).

Our major response variables were physical attacks, which we distinguish as aggressive, and a cheerr vocalization, which we consider reactive (with no necessary implication of aggression). Aggressive physical attacks included a range from brief contact with beak or feet to extended attack in which the male perched on the head or back of the mount and pecked vigorously. Attack was a binary variable scored as zero if the male did not attack the mount during the treatment period and one if he did. We used percentage of attacks per opportunity to compare responses for the binary attack variable among replicate subject males. Each male had two opportunities for attack, one on his own mount form and one on the dissimilar mount form, resulting in possible attack percentages of $0 \%, 50 \%$, or $100 \%$ for each replicate subject male. In the event of prolonged attack, we removed mounts to prevent their destruction. We also monitored subtler movements directed toward the treatments. These included various swoops and hovers, not involving contact with the treatments. We monitored arrival and departure times of subjects, as well as their proximity to the treatment and the center of their court.

The phonetically named cheerr vocalization was one of a repertoire of sounds produced by males. Males gave cheerr calls at high rates as a response to a threat (e.g., to snakes or male intruders), as well as at lower rates during high levels of display activity elsewhere in the lek arena, as occurs when females are present. We consider cheerr calls to be reactive, with no necessary implication of aggression. We tallied cheerr calls with hand counters while directly observing males, because tape recordings did not allow us to distinguish the focal subject from neighbors. When presentations were curtailed by vigorous attacks, we prorated the cheerr counts by the rate prior to the time of termination.

\section{Statistical Analysis}

Banded, court-holding males (subject males) served as the units of replication for the experimental treatments. The sample size of subject males was 17 throughout, except that we presented fewer lemon mounts to white- and golden-collared males ( $N=9$ and 7 , respectively; neither set used for statistical tests).

Multiple zeros (attacks) and relatively high variances (attacks and cheerr calls) suggested that our data might be skewed. We therefore estimated bootstrap confidence intervals for the means, for comparison to the $t$-test's normalitybased confidence intervals. For the percentage-of-attack data, one upper confidence limit for the bootstrapped means fell outside that of the normality-based interval. We therefore used Mann-Whitney tests, with corrections for ties, for tests involving percentage of attack. Because all bootstrapped intervals for cheerr calls fell within the normality-based confidence limits, a $t$-test even on somewhat skewed data should be conservative. We nevertheless log transformed the cheercall data before conducting $t$-tests (without assuming equal variances). We used the sequential Bonferroni adjustment of Hochberg (1988) to determine an overall significance threshold for our entire set of four hypothesis tests. Because we had a priori directional predictions for aggression under the sexual selection hypothesis, the attack rate tests were onetailed, whereas the cheerr (reactivity) tests were two-tailed. We used multiple regression tests to assess the possibility of observer and daily or seasonal temporal effects. None of the $F$ - or partial $F$-tests showed such effects (all $P$-values $>$ $0.29)$.

\section{RESULTS}

\section{Attacks on Manacus Taxidermic Mounts}

Lemon- and golden-collared males were more likely to attack than were white-collared males (Fig. 2). Golden-collared males attacked Manacus mounts significantly more than did white-collared males (Table $1 ; P<0.027$ under Bonferroni adjustment for all four hypothesis tests), demonstrating the inherent parental difference predicted by the sexual selection hypothesis. Contrary to the prediction of the nonsexual hypotheses, lemon-collared males were significantly 

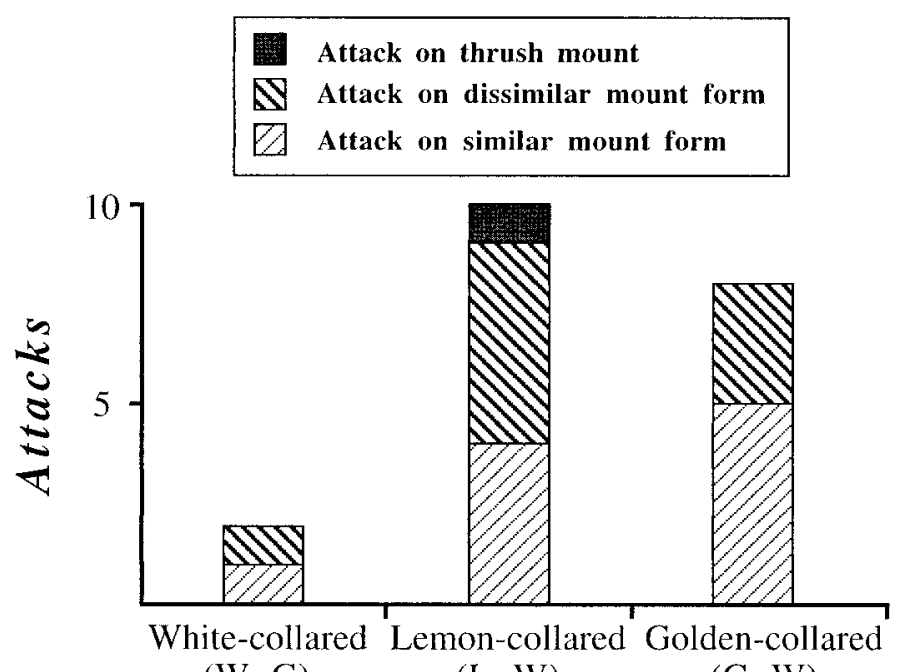

$(\mathrm{W}, \mathrm{G}) \quad(\mathrm{L}, \mathrm{W}) \quad(\mathrm{G}, \mathrm{W})$

\section{Subject male (treatments)}

FIG. 2. As predicted by the sexual selection hypothesis, goldencollared males attacked Manacus mounts (eight of 34 opportunities) at rates higher than those of white-collared males (two of 34 opportunities). As also predicted by the sexual selection hypothesis, lemon-collared males attacked Manacus mounts (nine of 34 opportunities) at rates higher than those of white-collared males, and comparable to those of golden-collared males. The only attack on a non-Manacus treatment was by a lemon-collared male on a thrush mount. Sample size throughout was 17 replicate subject males, each presented with one similar and one dissimilar mount treatment, for a total of 34 opportunities for attack on Manacus mounts. The parentheses refer to two treatment types presented to each type of subject male-similar and dissimilar mounts. The first parenthetical letter refers to the similar mount (e.g., W for white-collared). The second refers to the dissimilar mount-G for white-collared subject males and $\mathrm{W}$ for lemon- and golden-collared males. Hypothesis tests (Table 1) compared percentage of attacks by replicate subject males on the two Manacus mounts (each male could score $0 \%, 50 \%$, or $100 \%$ over his two opportunities). more likely to attack Manacus mounts than were white-collared males (Table $1 ; P<0.027$ ). The attack rate of lemoncollared males was similar to that of the aggressive goldencollared males (Fig. 2). Of the 17 replicate lemon-collared males, five attacked one of the two Manacus mounts presented to them and two attacked both mounts. Of the 17 replicate golden-collared males, six attacked one of the mounts and one attacked both mounts. Only two of the 17 replicate white-collared males attacked a mount, and none attacked both. The only attack on a non-Manacus mount was by a lemon-collared male on a thrush mount.

\section{Cheerr Calls and General Reactivity}

Several general patterns emerge from the cheerr data (Figs. $3,4)$. All three forms of subject males gave more cheerr calls to the Manacus mounts and the snake than they did to the thrush or stand-only control treatments (Fig. 3). The strong cheerr reaction by all three male forms to the snake treatment (Fig. 3) corroborated our expectation that cheerr calls serve as a general reaction to a perceived threat. When presented with the green, female-plumaged mount, six lemon-collared males averaged 61.3 cheerr calls, almost identical to the mean lemon-collared reaction to the neutral thrush mounts $(61.4$ calls). These results suggest that female-plumaged birds are not perceived as a threat and that plumage color is functionally important to male-male interactions.

Lemon-collared males gave the most cheerr calls to all treatment types (Figs. 3, 4). They gave significantly more cheerr calls to Manacus mounts than did either parental form (Table 1). Further, both white- and golden-collared subjects reacted to lemon-collared mounts with cheerr rates similar to those they gave to golden-collared mounts (Fig. 4), suggesting that lemon-collared males are perceived as essentially golden. Table 1 summarizes the results of the hypothesis tests based on cheerr and attack responses.

\section{Mixed Leks}

The main study sites did not contain a mixture of male forms, leaving open the possibility that direct experience with dissimilar individuals might influence behavior. We therefore

TABLE 1. Outcomes of experimental tests of the sexual selection hypothesis versus nonsexual alternatives concerning introgression of secondary sexual traits in the Manacus vitellinus/candei hybrid zone.

\begin{tabular}{|c|c|c|c|c|c|c|}
\hline Sexual selection predictions & Null (nonsexual) predictions & Subjects $^{1}$ & Treatment & $\begin{array}{c}\text { Mean cheerr calls/ } \\
30 \mathrm{~min} \pm \mathrm{SD}^{2}\end{array}$ & $\%$ Attacks & $P$-value ${ }^{3}$ \\
\hline $\begin{array}{l}\text { Golden-collared males attack more } \\
\text { than do white-collared males. }\end{array}$ & $\begin{array}{l}\text { Parental forms have similar at- } \\
\text { tack rates. }\end{array}$ & $\begin{array}{l}\mathrm{G} \quad(N=17) \\
\mathrm{W}(N=17)\end{array}$ & $\begin{array}{l}\mathrm{W}+\mathrm{G} \\
\mathrm{W}+\mathrm{G}\end{array}$ & - & $\begin{array}{r}23.5 \pm 31.2 \\
5.9 \pm 16.6\end{array}$ & 0.0269 \\
\hline $\begin{array}{l}\text { Lemon-collared males are more reac- } \\
\text { tive (cheerr calls) than golden-col- } \\
\text { lared males. }\end{array}$ & $\begin{array}{l}\text { Lemon-collared males resemble } \\
\text { parental forms in cheerr call }\end{array}$ & $\begin{array}{l}\mathrm{L} \quad(N=17) \\
\mathrm{G} \quad(N=17)\end{array}$ & $\begin{array}{l}\mathrm{L}+\mathrm{W} \\
\mathrm{G}+\mathrm{W}\end{array}$ & $\begin{array}{l}383.1 \pm 151.5 \\
195.9 \pm 80.2\end{array}$ & - & 0.0001 \\
\hline $\begin{array}{l}\text { Lemon-collared males are more reac- } \\
\text { tive (cheerr calls) than white-col- } \\
\text { lared males. }\end{array}$ & reactivity. & $\begin{array}{l}\mathrm{L} \quad(N=17) \\
\mathrm{W}(N=17)\end{array}$ & $\begin{array}{l}\mathrm{L}+\mathrm{W} \\
\mathrm{G}+\mathrm{W}\end{array}$ & $\begin{array}{l}383.1 \pm 151.5 \\
199.8 \pm 111.2\end{array}$ & - & 0.0002 \\
\hline
\end{tabular}

${ }_{1}^{1}$ Abbreviations for male subjects or taxidermic mount treatments: W, white-collared; L, lemon-collared; G, golden-collared.

${ }^{2}$ The score for each of the 17 replicate subject males was the mean of his response to two treatment types, as indicated in the treatments column.

${ }^{3}$ All $P$-values are shown prior to Bonferroni adjustment. Bonferroni-adjusted value over all tests was $P=0.0269$. 


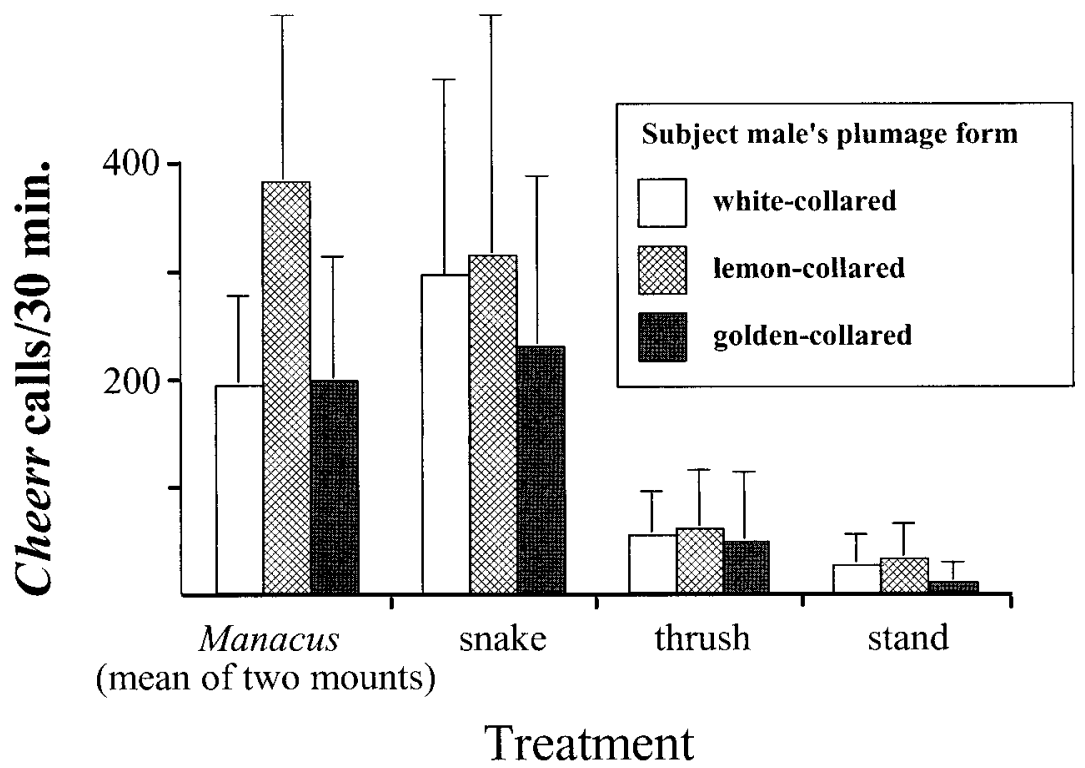

FIG. 3. Strong cheerr reaction, especially by lemon-collared males, to the Manacus and snake treatments as compared to the thrush and stand-only treatments. Note that the reaction of lemon-collared males differed most from that of the parentals (golden- or white-collared males) for the Manacus treatments. Reactions of lemon-collared males to the other treatments were much more similar to the parental reactions. Bars represent the mean number of cheerr vocalizations per 30-min treatment period ( \pm 1 SD). The bars for the Manacus taxidermic mount treatments represent the mean reaction of each subject form to presentations of two forms of Manacus taxidermic mounts (average of responses to similar and dissimilar mounts). Sample size throughout was 17 replicate subject males of each of the three plumage forms.

conducted supplementary experiments in the only mixed leks that exist, along the upper reaches of the Río Changuinola, where lemon- and white-collared males coexist. As in the pure leks, lemon-collared males were more aggressive (attacks) and reactive (cheerr calls) than were the white-collared males, regardless of the mount presented, although the small sample sizes precluded significance tests for any of the mixed-lek comparisons (Table 2). The major difference between the mixed and pure lek results was that both forms tended to respond more strongly in the mixed leks.

\section{Discussion}

The experimental results are consistent with the sexual selection hypothesis but contrary to the predictions of the nonsexual hypotheses. The results fall into three major categories. First, as predicted by sexual selection on male-male interactions, the parental forms differed in aggressiveness (Fig. 2, Table 1), with golden-collared significantly more likely to attack than white-collared manakins. Chapman (1935) also found high attack rates by golden-collared males in his pioneering experiments on Barro Colorado Island, approximately $12 \mathrm{~km}$ from our Pipeline Road study site. These results are also consistent with our experiences handling netted birds; golden-collared are much more energetic than are white-collared manakins. Collectively, these results suggest that upon initial contact between the parental forms goldencollared males may have had a particular advantage in dominance interactions, control of display courts, and other determinants of reproductive success.

Second, contrary to the nonsexual hypotheses (which predict that lemon-collared males should behave like white-collared), the attack responses of lemon-collared males were significantly greater than those of white-collared males and resembled, even exceeded, those of the golden-collared males (Fig. 2, Table 1). Again, these data are consistent with the idea that sexual selection favored heightened and undiscriminating responsiveness in lemon-collared males.

Third, the stronger cheerr reactivity of lemon-collared males than of either parental form to any of the three mount forms (Fig. 4) is consistent with sexual selection favoring golden-collared traits on initial contact. Aggression (attacks) and heightened reactivity (cheerr calls) toward males with appearance (plumage color and pattern) differing from the norm would likely have been favored more strongly at the incipient hybrid zone than in pure golden-collared leks. That is, golden-collared males responding strongly to white-collared males would gain benefits with few costs or risks of strong reciprocal response. The offspring of either pure or hybrid matings would therefore disproportionately represent the most aggressive and reactive of the golden-collared males. Introgressed lemon-collared males, because they are descendants of contact-zone males, reflect a history of selection for strong reaction to any plumage color or pattern that is like that of Manacus males. Such stronger-than-parental reactivity (Fig. 4, Table 1) would not be expected under the nonsexual hypotheses. That we saw the stronger-thanparental response in reactivity (cheerr calls) but not in aggression (attacks) hints at the possibility that aggression does carry associated risks or costs.

In summary, our results show significant differences in the behavioral responses of the three forms that suggest: (1) golden-collared males are more aggressive than white-collared males; (2) lemon-collared males are more aggressive than white-collared males; and (3) lemon-collared males are more 


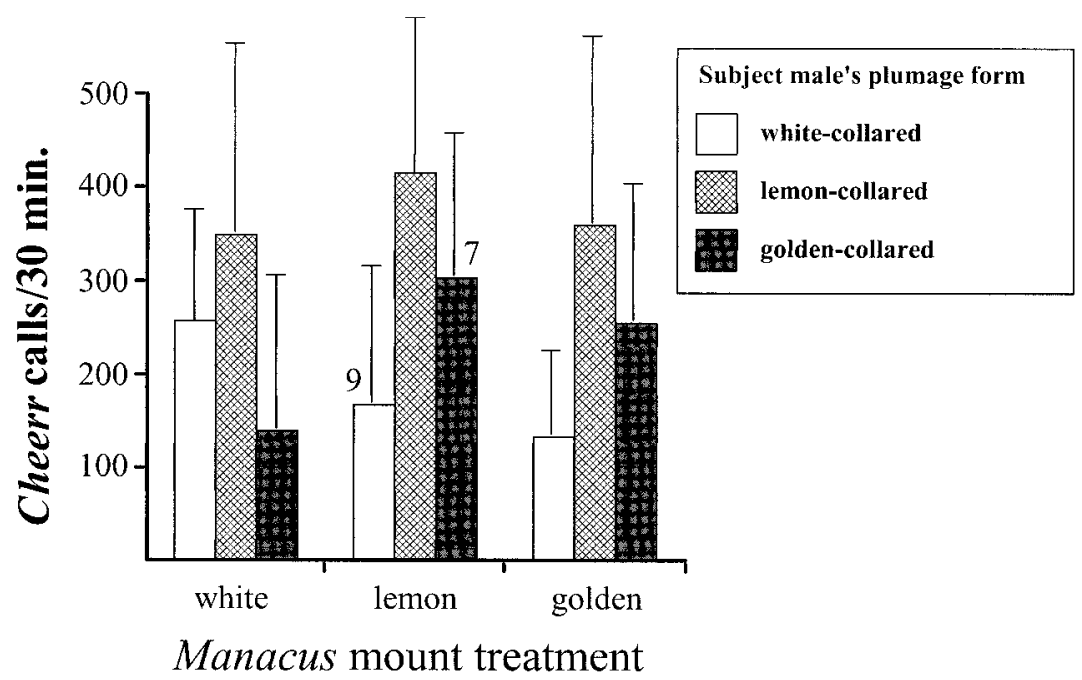

FIG. 4. Consistent with the sexual selection hypothesis, male lemon-collared subjects reacted with more cheerr vocalizations than did either parental form, regardless of the plumage form of the Manacus mounts presented to them. Bars represent the mean number of cheerr vocalizations per 30-min treatment period ( \pm 1 SD). Numbers above bars are those sample sizes that differed from the standard 17 subject males of each plumage form (these smaller samples did not enter in to comparisons used in statistical tests).

reactive (cheerr calls) than either parental form. The results refute the prediction of the nonsexual hypotheses that lemonand white-collared males should behave similarly. The results are consistent, however, with the hypothesis that sexual selection on male-male interactions drove functionally significant golden-collared traits, including not only plumage colors but also behaviors, across the hybrid zone to produce a region of introgressed lemon-collared males.

The cheerr data provide additional evidence for selection on plumage and behavior in lemon-collared males. The strong reaction to the model snakes by all three forms corroborated our suspicion that cheerr calls serve as a response to perceived threats. Although not necessarily aggressive, the cheerr calls at Manacus mounts showed that the subjects perceived the mounts as threats. The similarity of the cheerr reactions to lemon and golden mounts (as opposed to white mounts) by both of the parental forms further corroborates the functional similarity of lemon and golden as perceived by human observers and measured by reflectance spectrophotometry. That is, the manakins themselves also perceive lemon-collared males as essentially golden. The low level of reaction to female-plumaged mounts supports the hypothesis that variation in plumage color is functionally significant in the context of sexual selection on male-male interactions. We did not assess the response of court-holders to green males, but green males never hold courts and do not appear to pose a substantial threat to definitively plumaged court-holding males. McDonald (1993) showed that definitive male longtailed manakins responded much less aggressively to greenplumaged males than they did to definitively plumaged males.

As a follow-up to provide more complete support for the hypothesis of introgression driven by sexual selection, it would be useful to demonstrate unequivocally that increased aggression leads to increased reproductive success and that collar color affects the outcome of individual interactions between males or is linked to aggressive behavior either pleiotropically or by linkage disequilibrium. Several lines of indirect evidence support each of these points.

Aggression appears to influence reproductive success in manakins as well as other birds. Lill (1974) showed that more aggressive $M$. manacus males were more successful in obtaining courts and in mating. Olson and McDowell (1983) found that those $M$. manacus that consistently succeeded in displacing intruders had higher mating success. Aggression and dominance appear also to influence reproductive success in the context of hybridization. Male dominance rather than female choice explain the competitive advantage of mallards, Anas platyrhynchos, over American black ducks, A. rubripes (Brodsky et al. 1988). Evidence from other lek-mating species clearly indicates the general importance of male aggression and dominance status in determining male mating success (McDonald 1993; Höglund et al. 1994; Alatalo et al. 1996).

Behavior, in general, and aggression, in particular, may

TABLE 2. Response of males to taxidermic mounts in mixed leks along the upper Río Changuinola, compared to their response in pure leks.

\begin{tabular}{|c|c|c|c|c|c|}
\hline \multirow[b]{2}{*}{ Subject male } & \multirow{2}{*}{$\begin{array}{c}\text { Treatment } \\
\text { (mount type) }\end{array}$} & \multicolumn{2}{|c|}{ Attacks } & \multicolumn{2}{|c|}{ Mean no. cheerr calls/30 min } \\
\hline & & Mixed leks & Pure leks & Mixed leks & Pure leks \\
\hline White & white-collared & $1 / 4(25.0 \%)$ & $1 / 17(5.9 \%)$ & 217.5 & 257.5 \\
\hline White & lemon-collared & $1 / 4(25.0 \%)$ & $0 / 9 \quad(0.0 \%)$ & 277.1 & 168.1 \\
\hline Lemon & white-collared & $2 / 4(50.0 \%)$ & $5 / 17(29.4 \%)$ & 306.5 & 350.9 \\
\hline Lemon & lemon-collared & $2 / 4(50.0 \%)$ & $4 / 17(23.5 \%)$ & 404.8 & 415.2 \\
\hline
\end{tabular}


play larger roles in asymmetric avian hybrid zones than has previously been recognized. In addition, plumage differences appear often to reflect and even influence behavioral differences. The greater aggressiveness and competitive superiority of male Townsend's warblers (Dendroica townsendi) appears to be responsible for the moving hybrid zone between Townsend's and hermit warblers (D. occidentalis), with plumage playing a role as a badge of status (Rohwer and Wood 1998). Pearson and Rohwer (2000) experimentally demonstrated an asymmetry in parental aggression similar to what we found between white- and golden-collared males. An asymmetrical pattern of color variation occurs in a hybrid zone between two color morphs of the Australian magpie (Gymnorhina tibicen, Kallioinen et al. 1995). Experiments with dyed captives provided evidence for selection on color associated with differences in aggressiveness.

One plausible hypothesis stemming from our results is that hormone-mediated aggression and reactivity are the primary targets of selection, and that the lemon coloration is, at least in part, a correlated response to that selection. Schultz and Schlinger (1999) showed greater sensitivity of male than female golden-collared manakins to androgens in the spinal column, suggesting that diverse courtship behaviors respond to variations in hormone levels. Two studies of white-throated sparrows (Zonotrichia albicollis) provide evidence for a link between plumage variation and aggression. White-morph males were more likely to attack than were tan-morph males (Kopachena and Falls 1993), and white males were more vocally reactive (Collins and Houtman 1999). In addition, evidence exists for a pleiotropic effect of luteinizing hormone on both plumage color and agonistic behavior in female Quelea quelea (Lazarus and Crook 1973). Finally, Lank et al. (1999) showed that testosterone implants induced both male courtship behavior and male plumage polymorphisms in female ruffs (Philomachus pugnax).

The mixed-lek results provided one important check on our conclusions. It was plausible that prior experience might affect behavior. That is, where different forms coexist, experience might change responses to dissimilar forms. The mixed-lek results, although scant, did not differ qualitatively from those in the pure leks: Lemon-collared males were still more aggressive (attacks) and more reactive (cheerr calls) than were white-collared. Pearson and Rohwer (2000) described complex sorting of male aggressiveness across a wider, more spatially heterogeneous zone of mixed male forms in the Townsend's/hermit warbler hybrid zone. In the manakin system, the mixed-lek zone may currently be too narrow for any such sorting to occur.

Although we did not assess the role of female choice, malemale interactions may be sufficient to explain the observed introgression. Mount experiments in long-tailed manakins showed that plumage plays a critical role in male-male interactions (McDonald 1993), whereas variation in performance of courtship display explains patterns of female choice (McDonald 1989). In lek-mating black grouse (Tetrao tetrix) Höglund et al. (1994) found that dominance interactions, rather than attractive ornaments, were the primary determinants of male mating success. Nevertheless, several studies (see table 3.1 in Höglund and Alatalo 1995) have suggested a role for plumage or ornaments in female mate choice in lek-mating birds and the possibility of an additional influence through female choice remains.

It is important to place the results of the behavioral experiments in the context of the overall hybrid zone structure. Butlin and Neems (1994) suggested that the plumage color clines might not be shifted in position at all, but might simply be much wider than clines for the genetic and morphological characters. By extending the sampling of Parsons et al. (1993), Brumfield (1999) was able to reject this alternative explanation for the plumage cline shifts. Nevertheless, could the behavioral clines simply be wider than other clines? Although the number of sites sampled is limited, the geographic placement of the behavioral experiments allows us to reject that possibility. Specifically, the introgressed, lemon-collared males at sites 2 and 3 should have been less aggressive than the pure golden-collared males at site 4 . We found instead that lemon-collared males were actually more aggressive (Fig. 2).

It is natural to ask why golden-collared traits have not introgressed further, if they are under positive selection. It is probably not a coincidence that the boundary between lemon-collared and white-collared populations occurs at the Río Changuinola, the largest river in the region. The river may present a barrier to dispersal, which could, under some conditions, impede the advance of positively selected traits ( $\mathrm{Pi}$ álek and Barton 1997). Nevertheless, some mixing of lemonand white-collared birds occurs as the river narrows toward its headwaters (Fig. 1, site 3). The current situation may therefore constitute a rare temporal snapshot of introgression in action.

\section{ACKNOWLEDGMENTS}

A. Piñeda Jr., L. Horth, K. Gorrichátegui, and A. Cedeño helped with much of the fieldwork that made the study possible. A. Sangmeister, R. Blake, and D. Rubinstein assisted in the experimental presentations. The Chiriquí Land Company provided valuable logistical support in Changuinola. The Smithsonian Tropical Research Institute, in general, and M. Leone, N. Smith, and E. Bermingham, in particular, provided valuable logistical support or information. Autoridad Nacional del Ambiente in Panamá graciously provided permits and other logistical support. Funding came from the Smithsonian Scholarly Studies Program. K. Gerow provided invaluable statistical advice. R. Kimball, B. Schlinger, N. Korfanta, B. Crespi, S. Rohwer, and two anonymous reviewers provided helpful comments that greatly improved the manuscript.

\section{Literature Cited}

Alatalo, R. V., J. Höglund, A. Lundberg, P. T. Rintamäki, and B. Silverin. 1996. Testosterone and male mating success on the black grouse leks. Proc. R. Soc. Lond. B 263:1697-1702.

American Ornithologists' Union. 1983. American Ornithologists' Union check-list of North American birds. 6th ed. Allen Press, Lawrence, KS.

Avise, J. C. 1994. Molecular markers, natural history and evolution. Chapman and Hall, New York.

Barton, N. H. 1979. Gene flow past a cline. Heredity 43:333-339. 1993. Why species and subspecies? Curr. Biol. 3:797-799.

Barton, N., and B. O. Bengtsson. 1986. The barrier to genetic exchange between hybridising populations. Heredity 56:357-376. 
Barton, N. H., and G. M. Hewitt. 1989. Adaptation, speciation and hybrid zones. Nature 341:497-503.

Beehler, B. M., and M. S. Foster. 1988. Hotshots, hotspots, and the organization of lek mating systems. Am. Nat. 131:203-219.

Brodsky, L. M., C. D. Ankney, and D. G. Dennis. 1988. The influence of male dominance on social interactions in black ducks and mallards. Anim. Behav. 36:1371-1378.

Brumfield, R. T. 1999. Evolution of brilliant male plumage traits in Manacus. Ph.D. diss. Department of Biology, University of Maryland, College Park, MD.

Butlin, R. K., and R. M. Neems. 1994. Hybrid zones and sexual selection. Science 265:122.

Chapman, F. M. 1935. The courtship of Gould's manakin (Manacus manacus vitellinus) on Barro Colorado Island, Canal Zone. Bull. Am. Mus. Nat. Hist. 68:471-525.

Collins, C. E., and A. M. Houtman. 1999. Tan and white color morphs of white-throated sparrows differ in their non-song vocal responses to territorial intrusion. Condor 101:842-845.

Grant, P. R., and B. R. Grant. 1997. Genetics and the origin of bird species. Proc. Natl. Acad. Sci. USA 94:7768-7775.

Harrison, R. G. 1993. Hybrid zones and the evolutionary process. Oxford Univ. Press, New York.

Hewitt, G. M. 1988. Hybrid zones: natural laboratories for evolutionary studies. TREE 3:158-167.

Hochberg, Y. 1988. A sharper Bonferroni procedure for multiple tests of significance. Biometrika 75:800-802.

Höglund, J., and R. V. Alatalo. 1995. Leks. Princeton Univ. Press, Princeton, NJ.

Höglund, J., R. V. Alatalo, A. Lundberg, and O. Ratti. 1994. Context-dependent effects of tail-ornament damage on mating success in black grouse. Behav. Ecol. 5:182-187.

Jaarola, M., H. Tegelström, and K. Fredga. 1997. A contact zone with noncoincident clines for sex-specific markers in the field vole (Microtus agrestis). Evolution 51:241-249.

Kallioinen, R. U. O., J. M. Hughes, and P. B. Mather. 1995. Significance of back colour in territorial interactions in the Australian magpie. Aust. J. Zool. 43:665-673.

Kopachena, J. G., and J. B. Falls. 1993. Aggressive performance as a behavioral correlate of plumage polymorphism in the whitethroated sparrow (Zonotrichia albicollis). Behav. 124:249-266.

Lank, D. B., M. Coupe, and K. E. Wynne-Edwards. 1999. Testosterone-induced male traits in female ruffs (Philomachus pugnax): autosomal inheritance and gender differentiation. Proc. R. Soc. Lond. B Biol. Sci. 266:2323-2330.
Lazarus, J., and J. H. Crook. 1973. The effects of luteinizing hormone, oestrogen and ovariectomy on the agonistic behaviour of female Quelea quelea. Anim. Behav. 21:49-60.

Lill, A. 1974. Sexual behavior of the lek-forming white-bearded manakin Manacus manacus trinitatis Hartert. Z. Tierpsychol. 36: $1-36$.

McDonald, D. B. 1989. Correlates of male mating success in a lekking bird with male-male cooperation. Anim. Behav. 37: $1007-1022$

_ - 1993. Delayed plumage maturation and orderly queues for status: a manakin mannequin experiment. Ethology 94:31-45.

Moore, W. S. 1977. An evaluation of narrow hybrid zones in vertebrates. Q. Rev. Biol. 52:263-277.

Olson, D. H., and M. K. McDowell. 1983. A comparison of whitebearded manakin (Manacus manacus) populations and lek systems in Suriname and Trinidad. Auk 100:739-742.

Parsons, T. J., S. L. Olson, and M. J. Braun. 1993. Unidirectional spread of secondary sexual plumage traits across an avian hybrid zone. Science 260:1643-1646.

. 1994. Hybrid zones and sexual selection: response to Butlin and Neems. Science 265:122-123.

Pearson, S. F., and S. Rohwer. 2000. Asymmetries in male aggression across an avian hybrid zone. Behav. Ecol. 11:93-101.

Peters, J. L. 1927. A new manakin from Panama. Proc. N. Engl. Zool. Club 10:9.

Piálek, J., and N. H. Barton. 1997. The spread of an advantageous allele across a barrier: the effects of random drift and selection against heterozygotes. Genetics 145:493-504.

Rohwer, S. R. 1982. The evolution of reliable and unreliable badges of fighting ability. Am. Zool. 22:531-546.

Rohwer, S., and C. Wood. 1998. Three hybrid zones between hermit and Townsend's warblers in Washington and Oregon. Auk 115: 284-310.

Schultz, J. D., and B. A. Schlinger. 1999. Widespread accumulation of $\left[{ }^{3} \mathrm{H}\right]$ testosterone in the spinal cord of a wild bird with an elaborate courtship display. Proc. Natl. Acad. Sci. USA 96: $10428-10432$.

Shoemaker, D. D., K. G. Ross, and M. L. Arnold. 1996. Genetic structure and evolution of a fire ant hybrid zone. Evolution 50: $1958-1976$.

Snow, D. W. 1962. A field study of the black and white manakin, Manacus manacus, in Trinidad. Zoologica 47:65-104.

Corresponding Editor: B. Crespi 